Running Head: AUTHENTIC DATA WITH GEOSPATIAL TECHNOLOGIES

An Investigation of the Use of Real-Time, Authentic Geospatial Data in the K-12 Classroom

\author{
Aaron Doering \\ George Veletsianos \\ University of Minnesota
}

Correspondence concerning this article should be addressed to: Aaron Doering, Ph.D., 130D Peik Hall, 159

Pillsbury Dr. SE, Minneapolis, MN 55455, 612.625.1073, adoering@umn.edu.

Doering, A., \& Veletsianos, G. (2008). An Investigation of the Use of Real-Time, Authentic Geospatial Data in the K-12 Classroom. Journal of Geography, Special Issue on Using Geospatial Data in Geographic Education, 106(6), 217-225.

This DRAFT copy is provided only for reference. The definitive final version of this paper is available on the publisher's site. 


\title{
An Investigation of the Use of Real-Time, Authentic Geospatial Data in the K-12 Classroom
}

\begin{abstract}
This paper situates geospatial technologies as a constructivist tool in the K-12 classroom and examines student experiences with real-time authentic geospatial data provided through a hybrid adventure learning environment. Qualitative data from seven student focus groups demonstrate the effectiveness of using real-time authentic data, peer collaboration, and geospatial technologies in learning geography. We conclude with recommendations about geospatial technology curricula, geospatial lesson design, providing preservice teachers with geographic technological pedagogical content knowledge, and encouraging further research to investigate the impact, affordances, and pedagogical implications of geospatial technologies and data in the K-12 classroom.
\end{abstract}

Keywords: Geospatial Data, Adventure Learning, GIS, Google Earth, TPCK 


\section{An Investigation of the Use of Real-Time, Authentic Geospatial Data in the K-12 Classroom}

Geospatial technologies such as Google Earth (GE) and ArcExplorer allow individuals to view and examine the world through multiple layering of data within a spatial environment. Although access and use to such technology was previously limited by steep costs and demanding hardware, recently geospatial technologies have become increasingly popular with the general public. For example, the newcomer to geospatial technologies, Google Inc., reported that in 2006 Google Earth was downloaded more than 100 million times (Google 2006). Nor is Google Inc. the only company providing new geospatial technologies; recently Microsoft introduced Virtual Earth 3D and the Environmental Systems Research Institute (ESRI) introduced ArcWeb Explorer. The reasons for the popularity of geospatial technologies include improvements in computers' computational power as well as easier access to and a reduction in the cost of geospatial technologies and data (Milla, Lorenzo, and Brown 2005). Although geospatial technologies have become widely used and access costs have declined, the integration of such technologies within the classroom has been alarmingly slow (Kerski 1999; Baker and Bednarz 2003). Some of the reasons for this slow integration of geospatial technologies into the classroom include a dearth of research on its effectiveness (Baker and Bednarz 2003), design issues related to geographic information systems (GIS) and web-based geospatial technologies (Green 2001), a general lack of geographic pedagogical content models (Doering, Veletsianos, and Scharber, in press), a shortage of related curricula, low dissemination of geospatial technology into K-12 schools (Bednarz and Schee 2006), and non-existent and/or ineffective teacher training models (Doering 2006).

In response, this article seeks to understand the experiences of middle-school students using geospatial technologies to learn geography while utilizing real-time and authentic geospatial data from an adventure learning environment. Studying the experiences of these students will enable us to draw inferences about how geospatial data are utilized in the classroom, make recommendations on how geospatial technologies and data may be integrated in the K-12 curriculum, and propose future research related to the use of geospatial data in the classroom.

Situating Geospatial Technologies in Learning Theory

Prior to conducting this study, we hypothesized that through the provision of authentic data situated in a real-world context, its effortless integration within the geospatial technologies, and the elegant design and ease of use of new geospatial technologies, students would become motivated to use the data to learn geography within the 
classroom. Given that previous research has already highlighted the importance of authentic learning activities and collaboration among peers in enhancing educational outcomes (Bransford, Brown, and Cocking 1999; CTGV 1990; Herrington and Oliver 2000), the continuing integration of real-world data and collaborative practices into the classroom offers a promising pedagogical path when geospatial technologies are used as designed - specifically, as a constructivist tool (Kerski 1999).

Constructivist theory views learning as an active process that is constructed and perpetuated by the learner by means of associations with previous knowledge, interactions and collaborations with other individuals, and selfevaluation (Duffy and Cunningham 1996). The instructor is viewed as a facilitator and mentor who focuses on and encourages students’ reflective thinking and higher-order cognitive skills. For example, West (2003), discussing the role of GIS in the development of higher-order thinking skills and in motivating student learning, found that GIS positively influences students’ ability to utilize higher-level thinking skills within a context of enhanced relevance. This view of instruction starkly contrasts with the traditional view of the instructor as a knowledge provider who focuses on the memorization and reproduction of information.

In line with contemporary learning theories that view learning as a learner-centered, constructive, authentic, and situated process, Jonassen, Campbell, and Davidson (1994) extend the constructivist view of learning to educational technology. In their analysis, educational technology should focus on learning with media-that is, on learning in which media support and extend the pedagogical underpinnings of the classroom. This view focuses on pedagogy rather than the technology used in the classroom (e.g., geospatial technologies). Thereby, this analysis positions geospatial technologies and the use of geospatial data in the classroom as supportive technologies used by learners to construct new understandings of the world, not unlike the role that conventional media such as print maps have played in advancing learning. This argument has also been echoed in the geography literature. For example, Meyer et al. (1999) argue that we need to focus on "using GIS to learn how to do geography” rather than on learning how to use the technology. In other words, if the use of geospatial technologies merely enables learners to passively use and present data, learners will learn no more or no less than if the same actions were employed in a different medium. This result has been persistently observed by previous studies comparing the effects of different media on student performance and has been termed the no-significant-difference phenomenon (Russell 2001). 
This study, grounded in the understanding that geospatial technologies are a constructivist tool by which students can construct their own knowledge through the use of tools with authentic data, examines the effects of such an approach utilized in the area of adventure learning.

Situating Geospatial Technologies in Adventure Learning

Our research is situated in the work of an online hybrid adventure learning program entitled GoNorth! Arctic National Wildlife Refuge (ANWR). Adventure learning (AL) is a hybrid distance education approach that provides students with opportunities to explore real-world issues through authentic learning experiences within collaborative learning environments (Doering 2006). Specifically, this hybrid online learning environment includes a 300-page K-12 curriculum that works in conjunction with the travels of the scientists and educators of Team GoNorth! who dogsledded throughout ANWR from February to May. The curriculum, the travel experiences and observations of Team GoNorth!, and the online learning environment were delivered concomitantly so that students were able to make connections among what was happening in the real world, their curriculum studies, and the collaboration and interaction within the online learning environment (see http://www.polarhusky.com/2006/).

Every week, students had the opportunity to use multiple affordances of the online learning environment, which included trail reports, interviews, video clips, Quicktime ${ }^{\mathrm{TM}}$ virtual reality movies (QTVR), and sound recordings; expert chats comprising moderated synchronous discussions with topic experts around the world; collaboration opportunities with students and teachers around the world within the collaboration zones; and numerous geospatial technologies such as Google Earth that situated student learning within real-time, authentic data. For example, while students were studying a climate change module in their classrooms, Team GoNorth! collected climate change data (in the form of video clips, sound recordings, interviews, and reports) on the trail that were then posted on the online learning environment to support, supplement, and extend the curriculum. For instance, such data included interviews with Inuit Elders on traditional ecological knowledge, travel observations of Team GoNorth! members, latitude and longitude data, and data collected for NASA, all of which were integrated within the lesson plans.

The AL curriculum included the study of the region of travel, local case studies, and the integration of realtime authentic data to be analyzed with geospatial technologies. Each week, Team GoNorth! posted data supporting the learning of the module content on the GoNorth! learning environment. For example, when Team GoNorth! was 
traveling with the porcupine caribou herd and providing numerous location data in multiple media, students were studying migration in the curriculum module and were encouraged to complete the geospatial lesson on the migration of the porcupine caribou herd. Similarly, when students were studying the impact of climate change on a culture's "sense of place," students were encouraged to complete the geospatial lesson comparing the differing sense of place held by Team GoNorth!, the Inuits, and the students.. Figure 1 details the geospatial data flow within the AL interaction model (Doering 2006), in which data are provided by the experts to the learners and the teachers based on the AL content and then integrated within the geospatial lessons to provide an authentic experience for the students.

\section{--Insert figure 1 about here.--}

Two specific geospatial technologies were integrated within the AL curriculum - ArcExplorer Java Education for Educators (AEJEE) and Google Earth (GE). These two GIS programs, although very different in design and utility, were selected because they are free and can be used across computer platforms within K-12 classrooms. Students used the GIS programs to explore and study issues surrounding global climate change and the sense of place within their home state and the state of Alaska, the latter being the focus of the AL project. The geospatial lessons developed on Team GoNorth!'s area of travel and the desired curriculum outcomes were provided free within the K-12 curriculum, which used existing GIS and authentic real-time data provided by Team GoNorth! from the field. Every week, Team GoNorth! uploaded their coordinates, photos, and descriptions of their locations. For example, when Team GoNorth! was in the Gilbeau Pass in the Arctic National Wildlife Refuge, they uploaded their latitude and longitude coordinates, a description of the area, and a photo from this location (Fig. 2).

\section{--Insert figure 2 about here.--}

The specific lessons that were examined in this study included three AEJEE lessons - "An Alaskan Transect," “Climate Maps,” and “Caribou Tracking,” - and one GE lesson - "Sense of Place and GoNorth!” “An Alaskan Transect” documented the GoNorth! ANWR 2006 expedition transect. Students entered latitude and longitude data into AEJEE, detailing the expedition route data while also mapping the route. Acquiring the latitude and longitude coordinates sent from the trail, students hot-linked digital photos from the expedition as well as specific locale information to points along the route map. Students explored the data by adding map layers and analyzing the area through which the team was traveling and ultimately creating a complete transect map at the end of the expedition. During the "Climate Map" lesson, students took on the role of a scientist and developed snow cover maps that 
correlated snow depth with average temperature and elevation. Students acquired data, explored it through map layers, and predicted where Team GoNorth! would experience the greatest and least snow depth. Students also analyzed the factors that affected snow cover and considered what effect climate change may have on snow cover and average surface temperature on earth. Students also took the role of a scientist in the "Caribou Tracking" lesson, where they helped track the porcupine caribou herd. In this lesson, the students entered Global Positioning System (GPS) data into AEJEE to perform numerous analyses. Specifically, students acquired data, explored the data through adding map layers, and analyzed the data to come to a decision on the impact that oil exploration has had on the migration patterns and lives of the caribou.

Within the GE lesson on "Sense of Place and GoNorth!" students used GE to explore their home state and the state of Alaska while using real-time authentic data from the field to complete an Alaskan transect through the use of GE placemarks. Sense of place refers to an individual's perceptions regarding the environment in which he/she experiences daily life, environment being defined on a narrow-broad spectrum to refer to one’s neighborhood, hometown, region, state, country, etc. As such, sense of place is considered a constituent of cultural identity. In particular, students were asked to enter the coordinates, "visit" the location, and create placemarks to showcase the region. At the same time, the students were encouraged to note the latitude and longitude of their favorite location in their own neighborhood, make a placemark within GE, upload a photo and a description, and then share KMZ files encompassing this information with other students from around the world. (KMZ refers to a file format used in GE enabling a user to store a range of data including text, coordinates, photos, and placemarks within a self-contained electronic file.)

\section{Purpose of Study}

In this study, we sought to understand students' experiences learning geography when using Google Earth and ArcExplorer Java Edition for Educators within their classroom while utilizing real-time authentic data from an adventure learning environment. The students' task was to study issues surrounding global climate change and the sense of place within their home state and the state of Alaska, the focus of the adventure learning project.

Specifically, we sought to understand the following:

1. How does the acquisition and manipulation of real-time authentic data affect students' uses and perceptions of geospatial technologies when learning geography within the K-12 classroom? 
2. How does the acquisition and manipulation of real-time authentic data within a geospatial environment affect K-12 students' learning of geography?

3. How does collaboration and sharing of geographic data between students affect their learning of geography within the K-12 classroom?

Method

Participants

The participants in this study were 65 Caucasian middle-school students (45 girls, 20 boys) from two classrooms in the Midwest and one in the Northwest regions of the United States. All students interviewed used GE and 22 participants used AEJEE. None of the students had any prior experience using any form of geospatial technologies in the past and they all used a geography textbook as their main source for learning geography within their classroom. The middle-school students participating in this study were selected because their instructors used the adventure learning program along with the geospatial lessons within their classrooms.

\section{Data Sources}

All participants who completed the geospatial lessons participated in a focus group interview at the completion of the lessons. The focus groups lasted approximately one hour each and were audio-taped. Open-ended questions were used during the interview to prompt reflection among the students (see Appendix 1). Although three of the four lessons were using AEJEE, the GE lesson was used most often according to the students' teachers, as students were much more motivated to use and discuss GE within their classroom.

\section{Data Analysis}

Our research questions warranted a qualitative approach to data analysis that would help identify the students' experiences using GE. As Yin (1994) puts it, the case study method helps explain the "links in real-life interventions that are too complex for the survey or experimental strategies” (p. 15). Because this study focuses on the uses of GIS and authentic data within the classroom, it was essential that we use an approach that would help us understand complex and nuanced responses among participants.

We used a constant comparative method (Glaser and Strauss, 1967) to guide the development of the salient categories and patterns in the focus group and interview data. All focus group sessions were transcribed. We 
developed coding categories for the student focus group discussions based on several initial readings of the transcripts and research team discussions about salient categories. Transcripts were coded using Nvivo. After repeated individual readings of the transcripts to search for themes and patterns, the authors met four times to engage in lengthy and in-depth discussions regarding their individual findings. The initial codes that emerged and discussed were: 1) learners developing a sense of place, 2) the use of real-time authentic data in analysis, 3) the use of pre-existing data in analysis, 4) learners sharing data within their existing classroom and with classrooms throughout the nation, 5) the ease of access and use of GE, 6) exploring geographic spaces by "flying” through the spaces, and 7) the understanding of the region of study through the use of GE. These seven codes were further refined resulting in the emergence of data-driven patterns that were triangulated across the student focus groups and the individual researcher observations and analyses.

\section{Results}

The analysis of the focus group data indicates that the use of geospatial data within the geospatial technologies, especially GE, revealed five major findings. It (1) assisted learners in developing a sense of place through the use of authentic pre-existing data, (2) assisted learners in developing a sense of place through the use of authentic newly acquired data, (3) provided opportunities for the co-construction of knowledge through learnercreated data, (4) motivated students to explore geographic locations through ease of use, and (5) assisted learners in understanding the geography of the region studied through the use of newly acquired data. In relation to the research questions we posed, the study question, How does the acquisition and manipulation of real-time authentic data within a geospatial environment affect K-12 students' learning of geography? was answered by findings one, two and five; the study question How does collaboration and sharing of geographic data between students affect their learning of geography within the K-12 classroom? was answered by the finding three; and How does the acquisition and manipulation of real-time authentic data affect students' uses and perceptions of geospatial technologies when learning geography within the K-12 classroom? was answered by finding four. These findings will be discussed in turn.

\section{Developing a sense of place through authentic pre-existing data}

The first action students took was to use GE to explore their local neighborhood. In every focus group, all the students reported that the first place they had investigated was their home, demonstrating the natural curiosity of 
the students about their surroundings, especially when provided with relevant data and the technological tools that make such an investigation an easy and enjoyable task. Sami, for example, said, "I loved to be able to zoom in and out and see my home from a completely different perspective. I never knew my home was so close to the river. Also, the streets around my home are really weird.” Brenda noted that she “just couldn’t believe it. I was able to zoom in and see my parent's car, and then I was able to turn on [the data layers] where the local grocery stores are and see where I shop! It was incredible.” The students appeared to have studied their town from the view of an outsider visiting an unfamiliar place and noting interesting patterns. Jen noted that in their town, “The roofs all look exactly the same. I knew that the houses looked similar but I was surprised to see that every single house looked exactly the same” The exploratory nature of these investigations led students to interesting discoveries that would have not been possible had geographic data not been available through software that makes data visualization easy. Mark, for example, was eager to share that he had found a shorter path to walk home every day and had been using that path ever since. The authentic pre-existing data made available via GE enabled students to modify their view of the world and their concept of space. Students were able to see their hometown in relation to the bigger world and to observe relative sizes and locations. For example, Peter noted, “My house looked really, really tiny compared to everything else. I didn’t know there were so many other towns and homes surrounding my home.”

\section{Developing a sense of place through authentic, real-time newly acquired data}

Authentic, real-time acquired data refers to data collected by the students for their classroom activities and data provided to the students by Team GoNorth!. These data sets involved coordinates, pictures, and descriptions of the students' neighborhoods and Team GoNorth!'s locations during their traversal of the Arctic. Regarding these data sets, the students described in detail their excitement about collecting and using authentic geospatial data within GE. Ninety percent of the students stated that using GE in this way was one of their favorite tasks as they learned what their "teachers were trying to teach them.” Bill said, "I just couldn’t believe that there were people living in Alaska. I thought it was just all ice, a big ice chunk. I realized that it is well developed, there are cliffs and fields, and it seemed like I was there with the team.” Joan made a similar comment: “I thought people lived in igloos. I didn't know that there were big buildings in Alaska. I learned that there are people living there like in every other state.” 
Students used the geospatial data and the trail reports from Team GoNorth! in conjunction with each other. The trail reports included detailed textual descriptions, photographic materials, and video footage of the team's travels posted on the GoNorth! web site every week. Carla said, “This is how I like to learn. I could enter the locations and look at the actual places that we were studying. Also, we could then go online to the polarhusky site to see the movies where we could walk around like we were there.” Annie described how she used the data provided along with GE to reach an understanding of an apparent inconsistency: "When I saw it through GE I thought there must have been a mistake because it seemed that you [Team GoNorth!] were sleeping on the river. I used the pictures and coordinates in the lesson and I saw that you were actually sleeping on snow and ice, so I figured that the river was ice at the time.”

\section{Co-constructing knowledge through learner-created data}

Although only 20\% of the students using GE shared their KMZ files (the GE file format for exchanging files) within the online adventure learning environment, those students' experiences were discussed in great detail within the focus groups. All of the students from the Northwest region of the United States stated that it was valuable and motivating to be able to share details about their home and their town with other students from around the world. Sue said, "I never felt like where I live is special and that others want to learn about it. Now I do. I learned so much from looking at other [students'] files. It is just so cool!” Mark said, “I learned so much about other states from other students. I even did it at home with my parents.” Student responses indicated that the ability to share geospatial data with other students enabled a sense of connection to other parts of the country.

\section{Motivating exploration through ease of use}

Students in every focus group reported how easy it was to use GE and that they "just loved playing” with the software to explore the world around them. Unlike AEJEE, GE's default view includes data that students enjoyed exploring. Fourteen students equated the use of GE to video games that they played at home. Carl, for instance, said, "It was just so easy to use. I immediately started flying all around the world. It reminded me of my video games at home. When I got home, I asked my parents if we could download it and I just kept searching all these areas throughout the world.” This response takes on added significance in light of recent findings that video games can be viable learning tools that may redefine the educational landscape (FAS, 2006). 
Students also commented on how the ease of use contributed to their enjoyment of the GE technology, which they compared to the steep learning curve of some other technological tools they had used in their class. Simply put, learners could "jump in and start using it" without fear. Simon said, "Other times when we are going to use something in class, we spend so much time just learning about it. This one, we just started using and it was just so cool.”

Students also stated that they spent a great deal of time using the technology to explore major geographic landmarks and cities throughout the nation and throughout the world because of the ease of the technology. It appears that the ease of use and availability of geographic data motivated students to virtually explore geographic locations of interest. Jim said, "I immediately went to New York. Wow! It is as crazy as I thought it would be. There were buildings and cars everywhere!” Noah, after investigating the Grand Canyon, stated, “I had no idea how big that was! Have you been there? I could zoom in, turn it, and zoom in further. I really want to go there now.” Students also mentioned that they visited areas overseas such as the Australian outback, Beijing, Berlin, Cairo, and London. Betty commented, "I had no idea where Iraq was and how many buildings there were. It really opened my eyes.” She continued, "I also flew to Italy. I could see the boot from the air. How weird is that? I then zoomed right in and looked around.”

\section{Assisting learning through newly acquired data}

Although fewer students used AEJEE than GE within their classroom and those stated that it was much more difficult to use and “not as fun as Google Earth,” they also indicated that by using it, they learned a great deal about Alaska, the caribou, and the people who are affected by the caribou. Students stated they did not know there were caribou in Alaska and could not believe the dense population. Sara said, "After we figured out the software, it was really fun learning where the caribou are located and how they migrate. I had no idea they traveled in this way." Brad said, "I thought it was really neat to see the landscape of Alaska and then where the caribou are located. We went to the web site and we could see exactly where they were. We entered that information and it showed us how they were moving.” The students said they discussed in class why the caribou migrate and the impact that has on the local culture. They stated that not until they saw the images from Team GoNorth! did they really "get it." Sue said, "You know the pictures on the polarhusky site of the caribou? When the team is traveling with them and you can see them? That is when we really liked using it [AEJEE]. Also, it was so cool to be able to actually watch the caribou 
live on the movies! It was fun that we are studying this and seeing it at the same time!” Jessie said, "I know we wouldn't have liked it if we couldn’t actually see what was going on. It was fun using GIS, but it was much more real when we could read about what was happening and actually see photos and movies of it.”

\section{Discussion}

The use of geospatial technologies within the classroom still lags far behind what academics and organizations had hoped for a decade ago (Baker and Bednarz 2003; C. Fitzpatrick, personal communication, 2006). However, the call for additional research within the area of geospatial technologies (Baker and Bednarz 2003) and the progress geospatial environments have made toward becoming more user-friendly, may well contribute to an exponential increase in the use of geospatial technologies in the K-12 classroom in the near future. Students given access to GE are excited and motivated to use it, not only as part of their classroom assignments but as part of their free-time activities as well. This motivation appears to be fueling the use of GE inside and outside of the classroom as well as the sharing of data between users. Access to geospatial technologies and widely available data sets are spawning a generation of students who "love to explore" using computer software and many times are learning without making a conscious decision that it is time to learn. We have seen from the data within this paper that students are motivated to use geospatial technologies and data to explore their neighborhoods and regions throughout the world and when real-time acquired data are added to the equation, students become even more motivated. The adventure learning program added one more important dimension to student learning in that the data were authentic and available in real-time from a program that was taking place at the same time students were learning. Students enjoyed having access to the new data and media on a weekly basis from the GoNorth! trail reports that supported their investigations.

This study also suggests that the lack of specific geospatial technology curricula that has slowed its integration into K-12 classrooms may be overcome by the copious data built into new geospatial technologies that educators can integrate more easily into their current curriculum. Moreover, if educators are encouraged to link geospatial lessons to their current program outcomes, students may see the real-world relevance through the authentic geospatial data. Students need to be able to see how the use of the technology fits into the big picture of learning within their classroom. Moreover, if possible, students should have the opportunity to use real-time 
authentic data that the students produce themselves (e.g., by using GPS units, photographs, and textual descriptions of their surroundings) or acquire from experts within the field.

The weak dissemination of the geospatial technologies and support materials within the K-12 classroom may also be countered by using geospatial technologies within widely distributed and free online programs such as an adventure learning program like GoNorth! or lesson plans provided by organizations such as the National Geographic Society. Especially now that GIS technology is free and does not require specialized hardware, many educators may simply need relevant, authentic, and accessible lessons to motivate them to use the GIS technology within their classroom. As this study shows, adventure learning can increase this dissemination and teachers’ motivation to integrate geospatial technologies and data within their curriculum and classroom.

But even with these available geospatial technologies and data integrated within a free curriculum, we argue, the integration of geospatial technologies will not be successful until the design and development of preservice and inservice teacher education programs also include geographical technological pedagogical knowledge (G-TPCK) (Fig. 3). Based on the work of Shulman (1987), Mishra and Koehler (2006), Hughes (2000), and Hughes and Scharber (in press), we encourage seeing the three domains of technology (T), content (C), and pedagogy (P) as part of a whole when preparing teachers to teach with technology and develop curriculum that includes technology. For example, although the students within this study utilized geospatial technologies, the technology did not stand alone, but was linked to geographical content (CK) and pedagogical strategies (PK) through the AL curriculum to help teachers successfully integrate the geospatial technology lessons even if they did not have specific training in the geographical content. Thus we urge preservice teacher educators to consider the interconnections between technology, pedagogy, and technology, in the training of future social studies teachers so that they will understand the relevance of teaching and developing curricula that blend G-TPCK.

\section{- $\quad$ - Insert Figure 3 here - -}

Finally, we call for further research in geospatial integration within the K-12 classroom that focuses on the impact, affordances, and pedagogy of geospatial technologies and data. A meta-analysis of research on geospatial technologies within the social studies field (Doering, Scharber, and Veletsianos, unpublished manuscript) reveals a scarcity of studies on geospatial technology. We therefore encourage researchers, practitioners, and graduate students to see this as an important and valuable research area, moving to empirical quantitative and qualitative research that can fuel the transformation of theory into practice. 


\section{References}

Baker, T., and S. Bednarz. 2003. Lessons learned from reviewing research in GIS education. Journal of Geography 102:231-233.

Bednarz, S., and J. Schee. 2006. Europe and the United States: the implementation of geographic information systems in secondary education in two contexts. Technology, Pedagogy and Education, 15(2):191-205.

Bransford, J. D., A. L. Brown, and R. R. Cocking. 1999. How People Learn: Brain, Mind, Experience, and School. Report by Committee on Developments in the Science of Learning (with additional material from the Committee on Learning Research and Educational Practice), National Research Council. Washington, DC: National Academy Press. http://www.nap.edu/html/howpeople1/

Cognition and Technology Group at Vanderbilt (CTGV). 1990. Anchored instruction and its relationship to situated cognition. Educational Researcher 19(6):2-10.

Doering, A. 2006. Adventure learning: Transformative hybrid online education. Distance Education 27(2):197-215.

Doering, A. In press. Adventure learning: Situating learning in an authentic context. Innovate; Journal of Online Education.

Doering, A. 2006. Technology and teacher education: An investigation into pedagogy. Manuscript submitted for publication.

Doering, A., C. Scharber, and G. Veletsianos. 2006. A review of the research: geospatial technologies in K12 education. Unpublished manuscript.

Doering, A., G. Veletsianos, and C. Scharber. in press. Coming of Age: Research and Pedagogy on Geospatial Technologies within K-12 Social Studies Education. In Milson, A.J., and Alibrandi, M. (Eds), Digital geography: Geo-spatial technologies in the social studies classroom. Charlotte, NC: Information Age .

Duffy, T. M., and D. J. Cunningham. 1996. Constructivism: Implications for the design and delivery of instruction. In Educational Communications and Technology, ed. D. H. Jonassen, pp. 170-199. New York: Simon \& Schuster Macmillan

Federation of American Scientists (FAS). 2006. Harnessing the Power of Video Games for Learning. http://fas.org/gamesummit/Resources/Summit\%20on\%20Educational\%20Games.pdf

Glaser, B. G., and A. L. Strauss. 1967. The Discovery of Grounded Theory. Chicago: Aldine Publishing. GoNorth!: Arctic National Wildlife Refuge. 2006. http://www.polarhusky.com. 
Google. 2006. Google announces major imagery update For Google Earth: new tools and innovations in mapping, October 26, 2006. http://www.google.com/press/pressrel/geoday.html

Green, D. R. 2001. GIS: A Sourcebook for Schools. London: Taylor \& Francis.

Herrington, J., \& Oliver, R. 2000. An instructional design framework for authentic learning environments. Educational Technology Research \& Development 48(3):23-48.

Hughes, J. E. 2000. Teaching English with technology: Exploring teacher learning and practice. PhD dissertation, Michigan State University.

Hughes, J. E., and C. Scharber. In press. Leveraging the development of English-technology pedagogical content knowledge within the deictic nature of literacy. In Handbook of Technological Pedagogical Content Knowledge for Teaching and Teacher Education, AACTE Committee on Innovation and Technology. New York: Lawrence Erlbaum.

Kerski, J. 1999. A nationwide analysis of the implementation of GIS in high school education. In Proceedings of the 21st Annual ESRI User Conference. San Diego, CA. http:/gis.esri.com/library/userconf/proc99/ proceed/papers/pap202/p202.htm.

Meyer, J., J. Butterick, M. Olin, and G. Zack. 1999. GIS in the K-12 Curriculum: A cautionary note. Professional Geographer 51(4):571-578.

Milla, K., A. Lorenzo, and C. Brown. 2005. GIS, GPS, and remote sensing technologies in extension services: Where to start, what to know. Journal of Extension 43(3). http://www.joe.org/joe/2005june/a6.shtml.

Mishra, P., and M. Koehler. 2006. Technological pedagogical content knowledge: A framework for teacher knowledge. Teachers College Record 108(6):1017-1054.

Sanders, R., L. Kajs, and C. Crawford. 2001. Electronic mapping in education: The use of geographic information systems. Journal of Research on Technology in Education 34(2):121-129.

Shulman, L. 1987. Knowledge and teaching: Foundations of the new reform. Harvard Educational Review 57(1):122.

Yin, R. 1994. Case Study Research Design and Methods. Thousand Oaks, CA: Sage. 


\section{Appendix 1}

\section{Focus Group Questions}

1. Have you used geospatial technologies before doing this activity?

2. What geospatial technologies did you use?

3. What did you do when using the geospatial technologies?

4. How did you feel about using geospatial technologies?

5. What did you like about using geospatial technologies?

6. What didn't you like about using geospatial technologies?

7. What was your assignment when using geospatial technologies?

8. How many of you followed along with the adventure learning program last year and did you use geospatial technologies?

9. How did the geospatial lessons change your perception of your local space and the Arctic?

10. What are some things you learned about the Arctic, Arctic geography, geography in general?

11. What did you think about having real-time access to the data of the locations where the adventure learning team was located when using geospatial technologies?

12. How did your ability to use this data through geospatial technologies influence you?

13. How did you like about adding your own data to the geospatial technologies?

14. What types of data would you like to map with geospatial technologies?

15. Have you used geospatial technologies since finishing the assignment? 


\section{Figure Captions}

Fig. 1. Geographic data flow from experts to students and teachers.

Fig. 2. Real-time authentic data from the Guilbeau Pass in the Arctic National Wildlife Refuge.

Fig. 3. Geographic technological pedagogical content knowledge. 


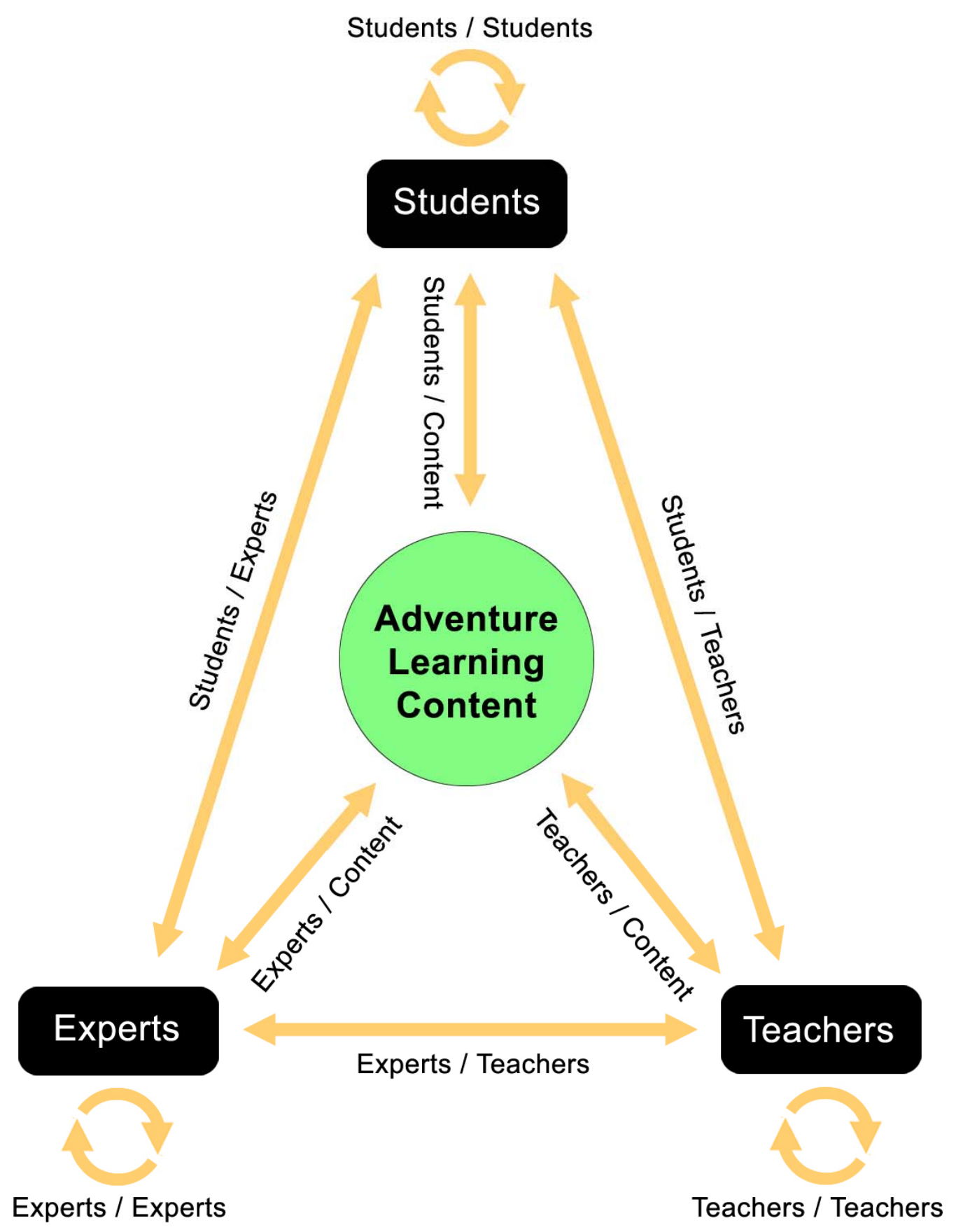


GET STARTED TEACHER LOUNGE EXPEDITION DOG YARD COMMUNITY INVESTIGATE ANUR CLIMATE CHANGE COLLABORATE! TIMBER NEUS ABOUT US

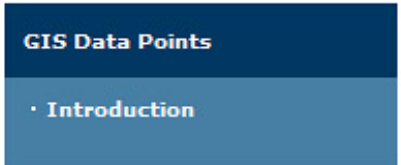

This Weeks Quick Links

- Earth Zone

- What is Climate?

- Field Research

- Expedition Scrapbook

\section{4\% GIS DATA POINTS Email this page 10 Print this page}

Throughout the live GoNorth! ANWR 2006 expedition (February - May 2006), Team GoNorth! will provide GIS data point information and images from various sites on the trail.

The latitude and longitude of any location on earth can be identified using a global positioning system (GPS). Upon identifying one's location, these GPS points can be used within a geographic information system (GIS) for geo-referencing of any location on earth. For example, you can overlay any type of map (physical, cultural, political) on top of your location and associate photos and data with your location which can then be used for investigation and data analyses.

Teacher Alert! This feature correlates with the GIS Activity 01 described in the Case Study of Module 01 - and available for download in the Download Center section.

Click here to learn more information on integrating GIS into your classroom.

GoNorth! Transect Route Data Points

$\begin{array}{ll}\text { Site } & \text { Date } \\ & \text { Location } \\ 2 & 2 / 13 / 06 \text { Expedition Basecamp } \\ 2 & 2 / 20 / 06 \text { Education Basecamp } \\ 3 & 2 / 27 / 06 \text { Alaskan Highway - Milepost } 0 \\ 4 & 3 / 06 / 06 \text { Fairbanks, Alaska } \\ 5 & 3 / 13 / 06 \text { Circle, Alaska } \\ 6 & 3 / 20 / 06 \text { Yukon River } \\ 7 & 3 / 27 / 06 \text { Fort Yukon } \\ 8 & 4 / 03 / 06 \text { Venetie } \\ 9 & 4 / 10 / 06 \text { Arctic Village }\end{array}$

$\begin{array}{llc}\text { Lat } & \text { Long } & \text { Arclink } \\ \text { (decimal degrees) } & \\ 41.150000^{\circ} & -86.100000^{\circ} & \text { image1 } \\ 44.978794^{\circ} & -93.238761^{\circ} & \text { image2 } \\ 55.757644^{\circ} & -120.235944^{\circ} & \text { image3 } \\ 64.846667^{\circ} & -147.719997^{\circ} & \text { image4 } \\ 65.816667^{\circ} & -144.050000^{\circ} & \text { image5 } \\ 66.485761^{\circ} & -145.213292^{\circ} & \text { image6 } \\ 66.550000^{\circ} & -145.266667^{\circ} & \text { image7 } \\ 67.033333^{\circ} & -146.466667^{\circ} & \text { image8 } \\ 68.116667^{\circ} & -145.533333^{\circ} & \text { image9 }\end{array}$




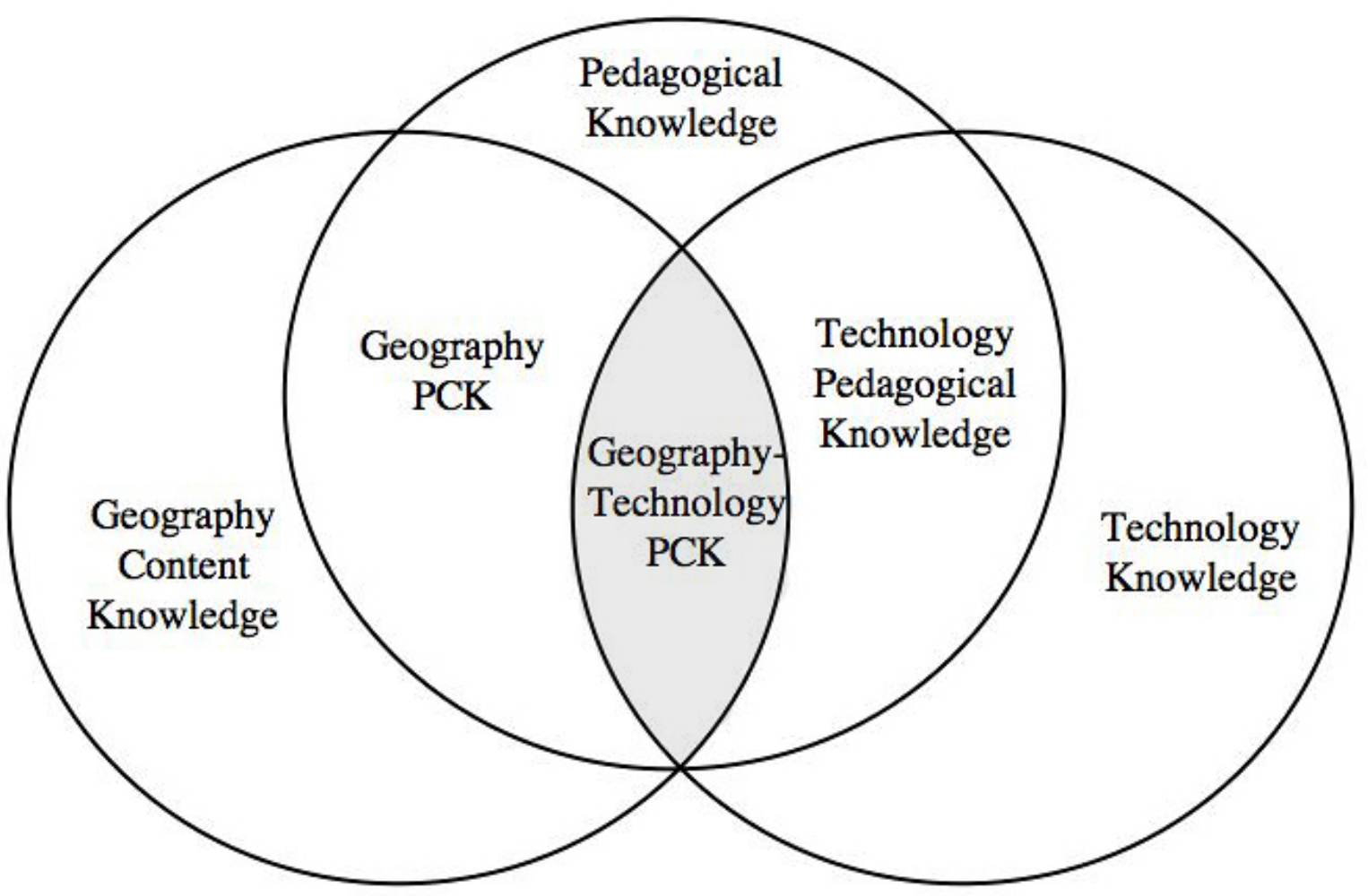

